\title{
Impact of academic integrity on workplace ethical behaviour
}

\author{
Jean Gabriel Guerrero-Dib ${ }^{1 *}$ (D), Luis Portales ${ }^{1}$ (D) and Yolanda Heredia-Escorza ${ }^{2}$ (D)
}

\author{
* Correspondence: jean.guerrero@ \\ udem.edu.mx \\ ${ }^{1}$ Universidad de Monterrey, Av. \\ Ignacio Morones Prieto 4500, 66238 \\ San Pedro Garza García, Nuevo \\ León, Mexico \\ Full list of author information is \\ available at the end of the article
}

\begin{abstract}
Corruption is a serious problem in Mexico and the available information regarding the levels of academic dishonesty in Mexico is not very encouraging. Academic integrity is essential in any teaching-learning process focussed on achieving the highest standards of excellence and learning. Promoting and experiencing academic integrity within the university context has a twofold purpose: to achieve the necessary learnings and skills to appropriately perform a specific profession and to develop an ethical perspective which leads to correct decision making. The objective of this study is to explore the relationship between academic integrity and ethical behaviour, particularly workplace behaviour. The study adopts a quantitative, hypothetical and deductive approach. A questionnaire was applied to 1203 college students to gather information regarding the frequency in which they undertake acts of dishonesty in different environments and in regards to the severity they assign to each type of infraction. The results reflect that students who report committing acts against academic integrity also report being involved in dishonest activities in other contexts, and that students who consider academic breaches less serious, report being engaged in academic misconduct more frequently in different contexts. In view of these results, it is unavoidable to reflect on the role that educational institutions and businesses can adopt in the development of programmes to promote a culture of academic integrity which: design educational experiences to foster learning, better prepare students to fully meet their academic obligations, highlight the benefits of doing so, prevent the severity and consequences of dishonest actions, discourage cheating and establish clear and efficient processes to sanction those students who are found responsible for academic breaches.
\end{abstract}

Keywords: Academic integrity, Academic misconduct, Higher education, Workplace behaviour, Work environment, Compliance, Ethics, Latin America, Mexico

\section{Introduction}

Corruption and dishonesty are deeply rooted problems and have a long history in many countries and communities and Mexico is no exception. There is usually more attention given to corrupt activities perpetrated by government authorities and public officers. The fact that many of these instances of corruption are carried out with the collusion of private sector businesses and individuals is largely ignored. Private citizens themselves are usually involved in corrupt activities where they can gain a personal benefit through the abuse of their position of power or authority (Rose-Ackerman and Palifka 2016).

Rose-Ackerman and Palifka (2016) affirm that personal ethical standards are one of the three categories of causes that promote corruption. This moral "compass" develops

(c) The Author(s). 2020 Open Access This article is distributed under the terms of the Creative Commons Attribution 4.0 International License (http://creativecommons.org/licenses/by/4.0/), which permits unrestricted use, distribution, and reproduction in any medium, provided you give appropriate credit to the original author(s) and the source, provide a link to the Creative Commons license, and indicate if changes were made. 
through a long and complex educational process which starts at home and, we could say, ends with death. Education becomes one of the key elements in the global strategy for the promotion of a culture of integrity and the fight against corruption. It is difficult to think that education can contribute efficiently if the phenomenon of academic dishonesty exists within the educational sphere. To develop a moral compass, it is not enough to know what has to be done, it is essential to do good (Amilburu 2005).

In almost every educational system in the world, it is a widely held view that all people must receive mandatory basic education, thus, almost all children and youths are subject to experience -or not experience- academic integrity during their education, a period that is long enough to develop habits. Daily behaviours during these mainly formative years may be considered as the standard that can perpetuate itself over time (Programa de las Naciones Unidas para el Desarrollo 2015).

In addition to the work carried out by the basic educational system, the university must fully form and develop the moral vision and purpose of its students, since it is not possible to consider professional education separate from ethical formation. Being a professional must include not only mastery of technical, practical and/or theoretical competencies, but also personal integrity and ethical professional behaviour that helps to give an ethical meaning to all university endeavours (Bolívar 2005). In so doing, academic integrity is necessary to learn and an essential requirement of academic quality.

Academic integrity is much more than avoiding dishonest practices such as copying during exams, plagiarizing or contract cheating; it implies an engagement with learning and work which is well done, complete, and focused on a good purpose - learning. It also involves using appropriate means, genuine effort and good skills. Mainly it implies diligently taking advantage of all learning experiences. From this perspective, experiencing and promoting academic integrity in the university context has a twofold purpose: achieving the learning intended to develop the necessary competencies and skills for a specific profession and, more importantly, developing an ethical perspective for principled decision making applicable to any context (Bolívar 2005).

Orosz et al. (2018) identified a strong relationship between academic dishonesty and the level of corruption of a country. Other studies (Blankenship and Whitley 2000; Harding et al. 2004; Laduke 2013; Nonis and Swift 2001; Sims 1993) demonstrate that students who engage in dishonest activities in the academic context, particularly undergraduate students, are more likely to demonstrate inappropriate behaviours during their professional life and vice versa.

From this point of view one can say that: the individual who is used to cheating in college, has a higher probability of doing so in the professional and work fields (Harding et al. 2004; Payan et al. 2010; Sims 1993).

Taking these studies in other parts of the world as a reference, the objective of the current work is to determine the relationship between the most frequent academic dishonesty practices, or lack of academic integrity amongst college students, and their predisposition to demonstrate ethical behaviour at work and in their daily lives within the Mexican context.

This research paper is divided into four sections. The first one presents a brief review of literature on academic integrity, academic dishonesty and its relationship with workplace ethical behaviour. The second section presents the methodology followed during the study, considering the design and validation of the instrument, data gathering, and 
the generation of academic dishonesty and ethical behaviour indexes. The third section shows the results of the analysis and its discussion. The last section displays a series of conclusions for the research presented, as well as its limitations and scope.

\section{Literature review}

Academic integrity

According to Bosch and Cavallotti (2016), the term integrity has four common elements that are included in the different ways to describe it: justice, coherence, ethical principles and appropriate motivation. Thus, a definition in accordance to this concept would be to act with justice and coherence, following ethical principles and a motivation focused on good purposes. In the educational context, academic integrity could be understood as the habit of studying and carrying out academic work with justice and coherence, seeking to learn and to be motivated by the service that this learning can provide others. However, there has been a wide variety of interpretations about this concept (Fishman 2016).

The International Center for Academic Integrity (ICAI), conceptualizes academic integrity as a series of basic principles which are the foundation for success in any aspect of life and represent essential elements that allow achievement of the necessary learning which enable the future student to face and overcome any personal and professional challenges (International Center for Academic Integrity 2014).

Academic integrity is considered a fundamental quality for every academic endeavour, essential in any teaching-learning process focused on achieving the highest standards of excellence and learning and thus, it must represent a goal to which every academic institution, seriously engaged in quality, must aspire to (Bertram-Gallant 2016). Enacting academic integrity means taking action with responsibility, honesty, respect, trust, fairness, and courage in any activity related to academic work and avoiding any kind of cheating or dishonest action even when the work is especially difficult (International Center for Academic Integrity 2014).

The current approaches to academic integrity provide ideas offering a conceptual framework, but there is still the need to specify concrete academic integrity behaviours characteristic of students such as: speaking the truth, complying with classes and assignments, carrying out activities by their own efforts, following the instructions given, providing answers on exams with only the material approved, citing and giving credit to others' work, and collaborating fairly during teamwork assignments (Hall and Kuh 1998; Von Dran et al. 2001). To these "observable" behaviours we must add a condition: that they must be preceded by the desire to learn in order to call them genuine manifestations of academic integrity (Olt 2002; Sultana 2018).

Despite the importance of the academic integrity concept, in most cases it is common to find an explanation of the concept in more negative terms that refers to behaviours that should be avoided. The general idea expressed in most honor codes is that academic integrity is to do academic work avoiding dishonesty, fraud or misconduct.

\section{Dishonesty and academic fraud}

Stephens (2016) argues that the problem of cheating is endemic and is at the root of human nature, thus it should not be surprising that it occurs. It is a strategy, conscious or not, used by humans to solve a problem. However, recognizing that cheating has 
always existed should not foster a passive and pessimistic attitude since human beings have a conscience that enables them to discern ethical behaviours from those that are not.

Understanding the phenomenon of dishonesty is important since the strategies used to try to counteract it will depend on this. For example, if dishonesty is considered a genetic disorder that some people suffer, the way to deal with it would be to identify those who suffer from it, supervise them, segregate them and/or try to "treat" them. If it is a common deficiency that everyone experiences to a greater or smaller degree, other kinds of tactics should be used to counteract it (Ariely 2013).

In general terms, there are different types of academic dishonesty that may be grouped into four major categories:

- Copying. Copying or attempting to copy from a classmate during an examination or assessment.

- Plagiarism. Copying, paraphrasing or using another author's ideas without citing or giving the corresponding credit to them.

- Collusion. Collaboration with someone else's dishonesty, and includes not reporting dishonest actions which have been witnessed. The most representative actions of this type of misconduct are: submitting assignments on behalf of classmates, allowing others to copy from you during an exam and including the names of people who did not participate in teamwork assignments or projects.

- Cheating. Among the most common actions in this category we find: using notes, technology or other forbidden materials during an exam; including non-consulted references; inventing or making up data in assignments or lab reports; contract cheating; distributing or commercializing exams or assignments; submitting apocryphal documents; impersonating another student's identity; stealing exams; altering grades; bribing individuals to improve grades.

The list is not exhaustive since it does not include every possible type of dishonesty. Every situation creates unique circumstances and different nuances so it should not be surprising that the emergence of "new" ways to threaten academic integrity arise (Bertram-Gallant 2016). Students' creativity and the continual development of technology will cause different manifestations of academic fraud (Gino and Ariely 2012), a fact that has been documented in university contexts in the past.

The results of recent research show that $66 \%$ of students have engaged in some type of academic misconduct at least once during their university education (Lang 2013). There are similar results in other studies carried out around the world. In the Mexican case, $84 \%$ of students in a Mexican university have witnessed a dishonest action during their education (UDEM 2018), and 6 out of 10 at another university have engaged in some kind of copying (UNAM 2013). In Colombia, a private university reported that $63 \%$ of the students accepted the addition of the name of a classmate that did not collaborate actively on a team assignment (EAFIT 2016). In England, half of the students would be willing to buy an assignment (Rigby et al. 2015). In Ukraine, $82 \%$ of students have used non-authorized support during exams (Stephens et al. 2010). While in China, $71 \%$ of students at one university admit to having copied a homework assignment from his/her classmates (Ma et al. 2013). 


\section{Academic dishonesty and its relationship with the lack of ethical professional behaviour}

Establishing a relationship between the level of corruption in a country and the level of academic dishonesty in its educational institutions is a difficult task to carry out since fraud and corruption have many different forms and causes, particularly in complex contexts such as the social dynamics of a country (International Transparency 2017). However, it can be established that academic dishonesty is a manifestation of a culture in which it is easy and common to break rules and where integrity is not as valued as it should be. Under this logic, it is possible to establish a certain relationship between a poor civic culture and academic dishonesty (García-Villegas et al. 2016).

This poor civic culture tends to be reflected in the daily activities of the citizens, particularly within organizations, where a relationship between students who cheat and unethical behaviour in the workplace has been identified (Winrow 2015). From this point of view, integrity and ethical behaviour, expressed in different terms such as decision making, conflict resolution or accountability, is one of the competencies most requested by employers (Kavanagh and Drennan 2008) and one of the critical factors needed to efficiently develop inter-organizational relationships of trust (Connelly et al. 2018). This is the reason behind the study, the understanding of this relationship.

A study carried out with 1051 students from six North American universities concluded that students who considered academic dishonesty as acceptable tended to engage in such activities and the same individuals tended to show unethical behaviour later during their professional lives (Nonis and Swift 2001). In another study with Engineering students, it was found that those who self-reported having engaged in dishonest actions, also carried it out in the professional field, which suggests that unethical behaviour shown at the college level continued into professional life (Harding et al. 2004). Findings of another study carried out at a nursing school demonstrated that students who showed academic dishonesty had a greater incidence of dishonest behaviour once they worked as health professionals (Laduke 2013).

In a study carried out with 284 psychology students who reported having engaged in some kind of academic dishonesty, specifically having copied during exams and lying in order to meet their obligations during their college education, also reported participating in actions considered illegal or unethical within the context of the research, specifically those related to substance abuse - alcohol and drugs, risky driving, lying and other sort of illegal behaviours. This data suggests that, besides the contextual factors, there are also individual causes such as attitudes, perceptions and personality traits that can influence the individual's behaviour in different aspects of their lives (Blankenship and Whitley 2000).

In one of the most recent studies, where data from 40 countries was collected, a strong relationship was identified between the self-reporting "copying in exams" of the student population and the level of corruption of the country, expressed in the corruption perception index published by Transparency International (Orosz et al. 2018).

Despite the increase in the number of studies related to academic integrity and ethical behaviour in the companies in different parts of the world since the 1990s, it has not been possible to identify any research in Mexico that explores the relationship between the ethical behaviour of an individual in his/her different life stages, as a college student and as a professional; or to put it differently, between academic integrity and ethical performance in the workplace. 


\section{Methodology}

This study followed a quantitative approach under a hypothetic - deductive approach. Since there is no suitable instrument available that explores the relationship between academic integrity and ethical behaviour, one designed for this study was used. It was based on questions from previous research instruments.

The "International Center for Academic Integrity" (ICAI) perception survey, created by Donald McCabe and applied to more than 90,000 students in the United States and Canada (McCabe 2016) was adapted with the addition of a section of questions related to personal and workplace ethical behaviour.

The McCabe survey (2016) consists of 35 questions that can be grouped into four sections. The first one explores the characteristics of the academic integrity programme, the educational atmosphere in general and the way in which the community is informed and trained in regards to current regulations. The second one requests information about the students' behaviour. It specifically asks about the frequency with which students are involved in dishonest activities at the moment and in previous academic levels, how severe they considered each kind of misconduct and their perception in regards to the level of peer participation in actions against integrity. The third section collects the opinions of the students regarding different statements related to academic work, faculty and students' engagement in the development of an academic integrity culture, strategies to fight dishonesty, the degree of social approval towards academic fraud, its impact and the perception of fairness in managing the cases of misconduct. The last group included demographic questions that contained basic information about the person answering the survey. The students were asked to provide their age, gender, marital status, nationality, place of residence, accumulated grade point average (GPA), programme he/she studies and the number of years at the university.

A section was added to this survey (Additional file 1) addressing the professional ethical behavioural construct. In this section, items from questionnaires described in Table 1 were used; all related to self-reporting of ethical behaviour. An additional validation was carried out for this instrument section through the assessment of experts from the internal control area of different companies and industries.

Except for a couple of open questions, the rest of the items used responses built under a five-point Likert scale to categorize their judgments in regards to the statements suggested. There are two types of responses used specifically: from totally agree

Table 1 Questionnaires and instruments used to address workplace ethical behaviour

\begin{tabular}{ll}
\hline Instrument & Author(s) \\
\hline $\begin{array}{l}\text { Questionnaire to measure behavior deviations } \\
\text { Questionnaire on behaviors considered dishonest } \\
\text { in the workplace. }\end{array}$ & $\begin{array}{l}\text { Blankenship and Whitley (2000) } \\
\text { Frequency Table for students who considered }\end{array}$ \\
$\begin{array}{l}\text { engaging dishonest actions in their environment } \\
\begin{array}{l}\text { Table of attitudes in favor of ethical behavior in a } \\
\text { non-academic context }\end{array}\end{array}$ \\
$\begin{array}{l}\text { Competency descriptors for "Ethics and Values" } \\
\text { and "Integrity and Trust" from the group } \\
\text { "Character and Behavior with Honor" }\end{array}$ \\
$\begin{array}{l}\text { Source: Created by the authors } \\
\text { Lawson (2004) }\end{array}$
\end{tabular}


to totally disagree about the perceptions and opinions; and always or never in the case of self-reported behaviours.

The responses were recorded automatically in the data base of the SurveyMonkey technology tool and values were assigned to each one of the responses in order to calculate an index per response, assigning a value of 5 to "Totally agree" and 1 to "Totally disagree" in a positive or favorable statement, and vice-versa, 1 and 5 respectively, in a negative or unfavorable statement.

The sample considers 1203 undergraduate and graduate students from a private university in northern Mexico who chose to respond to their professors' invitations to answer the survey as part of a diagnostic exercise that the university carries out periodically to learn about the students' perceptions regarding the degree of academic integrity culture on their campus. The participants were $51 \%$ women and $49 \%$ men. From them, $31 \%$ were in their first year, $25 \%$ the second year, $26 \%$ the third year, $11 \%$ the fourth year and only $7 \%$ had been studying for five or more years. Nearly $70 \%$ of the students still lived in their parents' homes and $42 \%$ reported having a good or outstanding average grade (higher than 80 over 100).

Once the data was collected, the internal validation of the instrument was done and indexes were generated for each one of the variables introduced into the model, through a factorial analysis of the main components. This type of analysis studies the relationship between a set of indicators or variables observed and one or more factors related to the research to obtain evidence and thus, validate the theoretical model (Hayton et al. 2004).

In order to define the indexes related to academic fraud and ethical behaviour there were three factorial analyses carried out, which took as selection criteria eigenvalues higher than one and varimax component rotation with the purpose to maximize the variances explained for each response and identify the items that represented the factors identified by the analysis itself in a linear way (Thompson 2004).

The first analysis considered questions related to the level of frequency with which specific dishonest actions were carried out. It included 27 items or questions in total, and five components accounted for $66.33 \%$ of the variance, with a KMO (Kaiser, Meyer and Olkin) of 0.955 and being significant for the Bartlett's sphericity test, a fact that shows the internal consistency of the indicator and its statistical validity. The five components were classified according to the weight that each question had in the rotated and stored components matrix such as regression variables to generate an indicator for each of them (Table 5 in Appendix). These indicators were defined as frequency in: 1) cheating in general, 2) copying in any way, 3) falsifying information, 4) using unauthorized support, and 5) plagiarizing or paraphrasing without citing.

The second analysis took the same criteria of the latter, but it only included the 27 questions related to how severe the misconduct or academic dishonesty was considered. The result was three components that accounted for $67.66 \%$ of the variance observed, with a KMO of 0.962 and the Bartlett's sphericity test was significant. The rotated components were classified and kept as a regression to generate three indicators, related to the perceived severity of: 1) cheating in general, 2) plagiarizing or copying and paraphrasing without citing, and 3) using unauthorized support (Table 6 in Appendix).

The third factorial analysis included the 47 questions related to the behaviour or ethical attitude of the respondents. This analysis generated six components that accounted 
for $64.54 \%$ of the variance observed, a KMO of 0.963 and the Bartlett's sphericity test was significant. When analyzing the components generated by the analysis, it was observed that four of them had only two questions with a weight greater than 0.4 in the rotated component matrix. Considering this situation, it was decided to eliminate these questions and a new factorial analysis was carried out considering only 39 questions. The result was two main components that accounted for $58.66 \%$ of the variance observed, with a KMO of 0.965 and the Bartlett's sphericity test was significant. The two components were classified into two indicators: 1) workplace ethical behaviour and, 2) personal ethical behaviour (Table 7 in Appendix).

Once the indicators for frequency and perceived severity of dishonesty or academic fraud, as well as those related to the behaviour or self-reported ethical attitude (workplace and personal) were generated, a linear regression analysis was carried out to determine how academic dishonesty influences a specific ethical behaviour.

\section{Results}

The linear regression analysis took as dependent variables the ones related to ethical behaviour self-reported by the respondents, and the frequency and severity of the academic dishonesty acts reported by the respondents as the independent variables. This analysis was carried out in two stages; the first one considered only the variable of the frequency with which academic dishonesty was reported, and the second one considered the variables related to the severity with which the respondents perceived these actions.

The first analysis took as independent variables the frequency of each component of self-reported academic misconduct: cheating in general, copying in any way, falsifying information, using unauthorized support, and plagiarizing or paraphrasing without citing. The result of the model was significant for the case of workplace ethical behaviour (sig. $=0.001$ ), accounting for only $3.4 \%$ of the variance observed (Table 2). In terms of analysis by variables, it was found that only the frequency of carrying out any kind of cheating, and copying in any way, had a significant impact on the workplace ethical behaviour of the respondents. The negative coefficient in both cases shows that a frequency reduction in academic misconduct, increased the self-reported workplace ethical behaviour (Table 2). The variables for falsifying information, using unauthorized support and plagiarizing didn't show significance.

In terms of personal ethical behaviour, the model proved significant (sig. $=0.000$ ) explaining $9 \%$ of the variance (Table 2) thus it may be stated that the severity of academic dishonesty influences personal ethical behaviour. In regards to the impact

Table 2 Results between frequency variables of academic dishonesty and ethical behaviour

\begin{tabular}{|c|c|c|c|c|c|c|c|c|}
\hline & \multicolumn{4}{|c|}{ Workplace Ethical Behaviour } & \multicolumn{4}{|c|}{ Personal Ethical Behaviour } \\
\hline & $\overline{C N E}$ & CE & Sig. & $\mathrm{R} 2$ & $\overline{\mathrm{CNE}}$ & CE & Sig. & R2 \\
\hline Cheating in general & -0.153 & -0.149 & 0.001 & 0.034 & -0.204 & -0.198 & 0.000 & 0.090 \\
\hline Copying in any way & -0.112 & -0.102 & 0.026 & & -0.148 & -0.135 & 0.002 & \\
\hline Falsifying information & -0.058 & -0.058 & 0.206 & & -0.148 & -0.148 & 0.001 & \\
\hline Using unauthorized support & 0.042 & 0.041 & 0.370 & & -0.022 & -0.022 & 0.624 & \\
\hline $\begin{array}{l}\text { Plagiarizing or paraphrasing } \\
\text { without citing }\end{array}$ & -0.071 & -0.068 & 0.133 & & -0.123 & -0.119 & 0.007 & \\
\hline
\end{tabular}

CNE Non-standardized coefficients, CE Standardized coefficients, Sig. Significance, R2 Adjusted R squared Source: Created by the authors 
level that the variables have on personal ethical behaviour, we found that only using unauthorized support did not prove significant. The remaining variables were significant and with negative coefficients, thus we may conclude that the lower the frequency of academic dishonesty reported by the respondents, the higher the reported personal ethical behaviour. In this sense, the variable of cheating in general had a greater weight in this kind of behaviour, followed by falsifying information and lastly plagiarizing.

The obtained results indicate that engaging in academic dishonesty with a greater frequency is directly and negatively related to the respondent's ethical behaviour and attitude. Therefore, it can be assumed that discouraging students from carrying out academic dishonesty will have a positive effect on their ethical behaviour, both in the work context as well as in their daily lives. In the same way, it was also found that respondents who performed academic dishonest activities less frequently, tended to have better ethical behaviour in general.

It is interesting to observe that the model does little to explain workplace ethical behaviour and that only the variable of cheating in general and copying had significant impacts on this behaviour. While in the case of personal ethical behaviour, academic dishonesty practices occurred more frequently and only the use of unauthorized support had no significant impact. This situation allows us to assume that academic dishonesty practices have a greater impact on daily ethical behaviour but less so in the workplace. This situation can be explained by the fact that organizations have codes of ethics and programmes which guide actions to be carried out by their personnel that are based on specific ethical and moral rules of conduct.

The second regression analysis took as independent variables the ones related to the perceived severity of the respondents in regards to cheating in general, copying and plagiarizing, and using unauthorized support. As in the previous case, the dependent variables were the ones related to the behaviour or ethical attitude in the workplace and in personal contexts. In regards to the workplace, we found that the model proved significant (sig. $=0.000$ ), explaining $10 \%$ of the variance observed (Table 3 ). Despite this result, the variable analysis showed that only the cheating in general variable had a significant impact on such behaviour with a positive coefficient, which means that the greater the perceived severity of the misconduct, the better the ethical behaviour within the organization.

In the case of personal ethical behaviour, the model also proved significant (sig. = 0.001), explaining only $5 \%$ of the variance observed in the indicator. In the case of workplace ethical behaviour, only the perceived severity of cheating in general variable had a significant impact on personal ethical behaviour. The positive coefficient of this variable enables us to establish that when any type of cheating was rated as severe, respondents tended to have better personal ethical behaviour (Table 3).

Table 3 Results between severity variables of academic dishonesty and ethical behaviour

\begin{tabular}{|c|c|c|c|c|c|c|c|c|}
\hline & \multicolumn{4}{|c|}{ Workplace Ethical Behaviour } & \multicolumn{4}{|c|}{ Personal Ethical Behaviour } \\
\hline & $\overline{C N E}$ & CE & Sig. & R2 & $\overline{C N E}$ & CE & Sig. & R2 \\
\hline Cheating in general & 0.311 & 0.323 & 0.000 & 0.100 & 0.218 & 0.239 & 0.000 & 0.050 \\
\hline $\begin{array}{l}\text { Plagiarizing, copying and paraphrasing } \\
\text { without citing }\end{array}$ & -0.032 & -0.032 & 0.575 & & 0.039 & 0.041 & 0.484 & \\
\hline Using unauthorized support & -0.086 & -0.093 & 0.105 & & 0.025 & 0.028 & 0.633 & \\
\hline
\end{tabular}

CNE Non-standardized coefficients, CE Standardized coefficients, Sig. Significance, R2 Adjusted R squared Source: Created by the authors 
The findings enable us to recognize the impact that the perceived severity towards cheating in general has on the ethical behaviour of the respondents, since it is the only variable that proved significant in the model. Hence, the extent to which students perceived the committing of any kind of cheating within the university as severe, their behaviour, both inside and outside the workplace, was more ethical.

Additionally, it is interesting to observe that the perception of the severity of cheating, plagiarizing or using any kind of unauthorized help does not have a significant impact on the ethical behaviour self-reported by the respondents. Therefore, it can be assumed that it is not as important to point out the severity of a specific act of academic dishonesty to influence the ethical behaviour of students and professionals, but rather to emphasize the severity of the misconduct that is associated with any act of academic dishonesty.

With the aim to identify the relationship that exists among all the variables of the model (frequency and severity), a third regression was conducted. This regression considered as independent variables, workplace ethical behaviour and personal ethical behaviour, and as dependent variables, the frequency and severity of academic misconduct. Both models, ethical behaviour in the workplace and personal, turned out to be significant. In the case of the workplace ethical behaviour, it was found that the model explains $9.1 \%$ of the variance of the indicator, while in the case of personal ethical behaviour, only $7.4 \%$ of the variance was explained (Table 4). Based on these results, it can be concluded that the lack of academic integrity generally affects people's ethical behaviour.

It is interesting to note that, in the case of ethical behaviour in the workplace, the only variable that was significant and positive was the severity of widespread dishonesty. That is, those respondents who considered any type of dishonesty as a serious offense had a greater tendency to be ethical in their workplace. This situation may be supported by the fact that academic integrity is presented in institutionalized spaces, such as school, university or business, and where the perception of greater severity tends to limit unethical behaviour within these institutions or organizations.

On the other hand, personal ethical behaviour was significantly influenced by the variables related to committing any act of academic dishonesty in general (frequency and

Table 4 Results between academic dishonesty and ethical behaviour

\begin{tabular}{|c|c|c|c|c|c|c|c|c|}
\hline & \multicolumn{4}{|c|}{ Workplace Ethical Behaviour } & \multicolumn{4}{|c|}{ Personal Ethical Behaviour } \\
\hline & CNE & CE & Sig. & R2 & CNE & CE & Sig. & R2 \\
\hline Frequency - Cheating in general & -0.094 & -0.060 & 0.333 & 0.091 & -0.240 & -0.161 & 0.010 & 0.074 \\
\hline Frequency - Copying in any way & -0.075 & -0.051 & 0.387 & & -0.028 & -0.021 & 0.731 & \\
\hline Frequency - Falsifying information & -0.029 & -0.021 & 0.733 & & -0.158 & -0.123 & 0.051 & \\
\hline Frequency - Using unauthorized support & -0.011 & -0.010 & 0.872 & & -0.028 & -0.029 & 0.649 & \\
\hline $\begin{array}{l}\text { Frequency - Plagiarizing or paraphrasing } \\
\text { without citing }\end{array}$ & -0.040 & -0.038 & 0.541 & & -0.124 & -0.125 & 0.047 & \\
\hline Severity - Cheating in general & 0.310 & 0.322 & 0.000 & & 0.209 & 0.229 & 0.000 & \\
\hline $\begin{array}{l}\text { Severity - Plagiarizing, copying and } \\
\text { paraphrasing without citing }\end{array}$ & -0.045 & -0.045 & 0.455 & & 0.009 & 0.009 & 0.879 & \\
\hline Severity - Using unauthorized support & -0.080 & -0.086 & 0.179 & & 0.029 & 0.034 & 0.602 & \\
\hline
\end{tabular}

CNE Non-standardized coefficients, CE Standardized coefficients, Sig. Significance, R2 Adjusted R squared 
severity). The negative sign in frequency indicates that those who reported having committed less academic dishonesty - whichever it may be - have better ethical behaviour on a personal level. In the same way, those who consider that committing academic dishonesty is something serious, also have a better ethical behaviour on a personal level. Another variable that was significant was the frequency in plagiarism or paraphrasing without citing, in the personal ethical behaviour, being those that had a lower frequency the ones that reported a better ethical behaviour.

The results of this third regression complement the findings of the first two regressions and allow to evidence the specific weight of considering academic dishonesty as a serious fault in people's ethical behaviour.

\section{Discussion}

Based on the results generated in the previous section, some reflections and conclusions can be drawn related to academic integrity, academic misconduct, and ethical behaviour.

The respondents' ethical behaviour shows a relationship to the practice of academic dishonesty, both in terms of the frequency with which they carry out these acts, as well as the severity they assign to them. The more severe the students consider an act of academic dishonesty, the more ethically they behave outside of the university. Likewise, it is important to establish measures to discourage or reduce the number of acts of academic misconduct, since the habitual practice of unethical actions may promote a normalization of these behaviours, and reduces a student's interest in practising ethical behaviours after graduating from college. It is important to disclose a basic assumption, that a person faces ethical dilemmas first, in an educational environment and later, in a workplace context. This situation suggests that, since academic integrity is usually experienced earlier than workplace ethical behaviour in a person's life, the former may influence the latter.

These results encourage the reflection on the importance of student perceptions about academic dishonesty and the opportunities they have to act on these dishonest practices. Interestingly, in terms of perception, students who have developed a conscience about the severity of any kind of cheating in an academic setting, exhibit a greater degree of ethical behaviour. Likewise, when a student frequently practices academic misconduct shows less ethical behaviour within other contexts. These findings add another reason why higher education institutions should establish systematic programmes focused on promoting a culture of academic integrity to convince students of the severity of these unethical actions, to discourage them from committing them and to punish them if the previous endeavours do not work.

The results of this study suggest that it is not enough to teach academic integrity in a theoretical or conceptual way, but that it is learned and acquired through real contexts and practices, where the prevention or discouragement of gaining benefits through misconduct contributes to student learning and development. This learning goes beyond the classroom and the university context and becomes an ethical behavioural pattern in the work and personal environments. Likewise, organizations should have ethical codes and other elements of a business ethics and 
compliance programme to foster a culture of integrity and continue the formative process started within educational institutions.

It can be stated that a part of a professional's ethical behaviour is related to their awareness of the risks or severity of getting involved in academic dishonesty, as well as having the opportunity to engage in these acts. For this reason, it is not enough to convince students of the importance of following integrity criteria, it is also necessary to create an environment where cheating or deceptions are very difficult to practice. It is essential that students are convinced to act with integrity during their college years and that they are made aware of the risks or penalties that come with not doing so. This will strengthen a positive behavioural pattern in different contexts of their lives, and encourage them to become ethical professionals, business people, and citizens.

It is essential for higher education institutions to demonstrate a commitment to building a culture of academic integrity, both in terms of their awareness and their practice, since through them the ethical behaviour of students and future graduates is strengthened and forged. In this respect, the university campus is featured as a favourable environment to train individuals and promote ethical behaviour within and outside the university, meeting its commitment to the community and the world to develop more ethical and engaged citizens who do things well in all aspects of their lives.

\section{Conclusions}

There has been little research published regarding the relationship of students perceptions about their behaviour on academic integrity in schoolwork, and on professional performance. This study, like the ones identified previously, points out a relationship that can and should be explored in greater depth. Academic integrity - concept, benefits, strategies - and its counterpart, academic dishonesty - frequency causes, consequences, management - have not received, in México and Latin America, the attention they have earned in other countries and regions.

Considering that corruption is a major problem afflicting Mexican society and that academic dishonesty is related one way or another with corruption, it becomes particularly important to understand the academic dishonesty phenomenon in depth.

In order to achieve this, it is necessary to invest resources to identify the strategies which most effectively promote academic integrity, because doing so, not only prevents fraud and economic losses, but also builds the foundations of a more humane and fair society, resulting in a common interest. Viewed from this perspective, academic integrity is not an issue that should be addressed only within educational institutions, but it should also awaken the interest and the action of the business and production sectors.

\section{Limitations of the research}

The instrument used to collect information for this research project was a survey created with the support of others and thus the questions have only been validated in this exercise.

It is a self-reporting tool regarding ethical behaviour, that is, it reflects the selfreported participants' perceptions of themselves and not about their own behaviours. This situation shows two limitations. The first one is that it does not discuss behaviours per se, but the perception participants have about them. The second limitation is that 
the results are subjected to the biases of the same person who self-reports. The results depend not only on the "objectivity" of respondent's perception but also on the sincerity with which each question is answered. Despite the prevailing atmosphere of illegality, it is still desirable to seem somewhat honest to others. Additionally, the application of the survey was done via an electronic format on the personal devices of the participants, which can raise suspicions about the true anonymity of the participants' responses.

Self-reported surveys leave aside the profound answers related to the causes of correlations found. A qualitative approach to the phenomenon could complement our results and lead to a more in depth analysis of the relationship between corruption and/or unethical behaviour and academic dishonesty in the Mexican context.

Another important limitation of the study, derived from its exploratory perspective, is that the instrument did not consider as a relevant variable the employment situation, years of work experience or hierarchical level of the respondents. This limitation causes the self-report of ethical behaviour in the workplace to be presented in a general way and not with a greater level of depth. However, the results found in this research and the identification of the relationship between academic integrity and ethical work behaviour in an exploratory way, open the door for studies where it is sought to deepen the understanding of this relationship that was identified by this study, as mentioned in the next section.

\section{Implications for future investigations}

As mentioned in the previous section, the following works related to the study of the academic integrity and ethical behaviour of individuals could point to the confirmation of the results found in this research. These future studies could be based on the causal relationships found in this research, which were generated based on the review of the literature and the assumptions that arise from it. In this sense, the use of structural equations is necessary as a method of confirmation from a quantitative perspective, as well as the use of a qualitative approach that contribute to a better understanding of this phenomenon. This study is a first step towards the realization of scientific research that demonstrates the impact that efforts to promote academic integrity in universities have on the ethical behaviour of its students and graduates.

It would be useful to replicate the research by gathering information periodically to validate the results and/or conduct a longitudinal study that allows monitoring of the "real-time" habits of the different graduating classes over time. Thereby, self-reporting of what happened at each moment in time would be collected and would enable researchers to explore different associations.

Many questions still remain unanswered in the Mexican context: What is academic integrity? How is it experienced? How is it perceived? How is it assessed? What are the benefits in doing so? What are the most appropriate strategies? What are the levels of academic dishonesty? Who carries it out? Why do they do it? What are the reasons that cause it? What is the mindset of people that behaves ethically? What are the reasons why someone turns out to be more or less ethical? How should it be addressed and managed? What consequences does it trigger? What role do professors and other educational stakeholders play? What is the impact of technology? 


\section{Appendix}

Table 5 Rotated matrix of the factor analysis for the questions about frequency of the misconduct or academic dishonesty is considered

\begin{tabular}{ll}
\hline Question & $\begin{array}{l}\text { Cheating } \\
\text { gener }\end{array}$ \\
\hline j.My behavior is congruent with my beliefs. & 0.836 \\
g.l say the truth. & 0.812 \\
k.I recognize my qualities and defects. & 0.780 \\
h.It's easy for me to tell the truth. & 0.755 \\
r.l try to ensure that each person is treated & 0.727 \\
fairly, even if is someone that I do not know. & \\
i.l express what I think and feel without & 0.724 \\
keeping up appearances. & \\
a.l keep promises. & 0.714 \\
ff. I am persistent to / until reaching my & 0.698 \\
goals. & \\
c.People trust me. & 0.689 \\
cc. I accept my mistakes and rectify. & 0.654 \\
pp. I trust my ability and my own talents. & 0.651 \\
I.Being honest is more important than my & 0.620 \\
personal interests. &
\end{tabular}

0.813

0.785

y.l give bribes or kickbacks to obtain benefits.

u.l get in line (skip places).

s.l consume piracy products.

m.l do things just to look good.

0.751

o.l think the end justifies the means.

0.737

qualities or achievements.

z.l speak badly of others.

0.702

0.676

0.667

oo. I dedicate time only to the things that interest me.

kk. I strive to recognize the needs of others.

0.732

0.705

0.629

II. I perform actions seeking the good of others.

v.When driving, I respect speed limits.

w.I comply with the laws that govern my country.

x.l treat others with respect.

ee. I assume consequences for my decisions and actions.

p.l return what is not mine.

rr. I do what I must do even when facing adverse circumstances.

dd. I analyze prudently the possible consequences of the different alternatives for action before making a decision.
0.659

0.641

0.434

0.363

0.329

0.375 
Table 6 Rotated matrix of the factor analysis for the questions about how severe the misconduct or academic dishonesty is considered

\begin{tabular}{llll}
\hline Question & $\begin{array}{l}\text { Cheating } \\
\text { in general }\end{array}$ & $\begin{array}{l}\text { Plagiarizing or copying } \\
\text { and paraphrasing } \\
\text { without citing }\end{array}$ & $\begin{array}{l}\text { Uning } \\
\text { unauthorized } \\
\text { support }\end{array}$
\end{tabular}

j.Copying from another student during a test or examination $\quad 0.857$ WITHOUT his or her knowledge.

i.Copying from another student during a test WITH his or $\quad 0.842$ her knowledge.

u.Using an electronic/digital device as an unauthorized aid during an exam.

cc. Cheating on a test in any other way.

k.Using digital technology (such as text messaging) to get unpermitted help from someone during a test or examination.

f.Helping someone else cheat on a test.

r.Submitting a paper you purchased or obtained from a website and claimed it as your own work. during a test or exam.

p.Turning in a paper from a "paper mill" (a paper written and previously submitted by another student) and claiming it as your own work.

y.Turning in work done by someone else.

w.Turning in a paper copied, at least in part, from another student's paper, whether or not the student is currently taking the same course

h.Fabricating or falsifying research data.

q.Paraphrasing or copying a few sentences of material from an electronic source - e.g., the internet - without footnoting them in a paper you submitted.

o.Paraphrasing or copying a few sentences from a book, magazine, or journal (not electronic or web-based) without footnoting them in a paper you submitted.

bb. Using Cliff Notes or Spark Notes and not citing.

z.Receiving requests from another person (in person or using electronic means) to copy your homework.

x.Using a false or forged excuse to obtain an extension on a due date or delay taking an exam.

n.Copying (using digital means such as Instant Messaging or email) another student's homework.

m.Copying (by hand or in person) another student's homework.

aa. Submitting the same paper in more than one course without specific permission.

I.Receiving unpermitted help on an assignment.

v.Copying material, almost word for word, from any written

g.Fabricating or falsifying lab data.

0.448

b.Working on an assignment with others (in person) when the instructor asked for individual work.

c.Working on an assignment with others (via email or Instant Messaging) when the instructor asked for individual work. 
Table 7 Rotated matrix of the factor analysis for the questions related with workplace and personal ethical behaviour

\begin{tabular}{|c|c|c|}
\hline Question & Workplace & Persona \\
\hline bb. I use company resources for personal reasons. & 0.867 & \\
\hline t.l evade taxes. & 0.860 & \\
\hline $\begin{array}{l}\text { aa. I treat collaborators or work peers incorrectly or } \\
\text { abuse verbally (make rude, insulting or shameful comments). }\end{array}$ & 0.857 & \\
\hline ii. I reveal confidential information to unauthorized persons. & 0.845 & \\
\hline $\begin{array}{l}\text { n.I distort information in reports or presentations to make } \\
\text { them seem they had a better performance. }\end{array}$ & 0.825 & \\
\hline y.l give bribes or kickbacks to obtain benefits. & 0.811 & \\
\hline $\begin{array}{l}\text { f.l call in sick without being so, as an excuse to be absent to } \\
\text { work. }\end{array}$ & 0.810 & \\
\hline $\begin{array}{l}\text { gg. I make up excuses to avoid meeting my work and } \\
\text { responsibilities. }\end{array}$ & 0.800 & \\
\hline ss. I blame others of my own failures or actions. & 0.796 & \\
\hline $\begin{array}{l}\text { tt. I do things even when I think they are incorrect only not } \\
\text { to have a bad image in the eyes of others. }\end{array}$ & 0.793 & \\
\hline s.l consume piracy products. & 0.788 & \\
\hline u.l get in line (skip places). & 0.778 & \\
\hline z.l speak badly of others. & 0.734 & \\
\hline m.l do things just to look good. & 0.728 & \\
\hline hh. I waste time during the work day. & 0.722 & \\
\hline e.l use unethical strategies to achieve my objectives. & 0.717 & \\
\hline $\begin{array}{l}\text { nn. I feel bad for other people's assets, qualities or } \\
\text { achievements. }\end{array}$ & 0.705 & \\
\hline o.l think the end justifies the means. & 0.697 & \\
\hline $\begin{array}{l}\text { d.I use my position or the information I have to obtain } \\
\text { personal benefits. }\end{array}$ & 0.615 & \\
\hline $\begin{array}{l}\text { uu. I remain silent before others' faults and cheating because } \\
\text { of fear for reprisals. }\end{array}$ & 0.571 & \\
\hline
\end{tabular}

j.My behaviour is congruent with my beliefs.

ee. I assume consequences for my decisions and actions.

r.l try to ensure that each person is treated fairly, even if is someone that I do not know.

g.l say the truth.

q.l give other's work credit.

ff. I am persistent to / until reaching my goals.

x.I treat others with respect.

c.People trust me.

k.l recognize my qualities and defects.

h.lt's easy for me to tell the truth. 0.741

$\begin{array}{ll}\text { a.l keep promises. } & 0.727\end{array}$

$\begin{array}{lr}\text { cc. I accept my mistakes and rectify. } & 0.720\end{array}$

$\begin{array}{ll}\text { p.l return what is not mine. } & 0.710\end{array}$

dd. I analyze prudently the possible consequences of the 0.708

different alternatives for action before making a decision.

$\begin{array}{ll}\text { II. I perform actions seeking the good of others. } & 0.707\end{array}$

l.Being honest is more important than my personal interests. $\quad 0.695$

$\begin{array}{ll}\text { i.l express what I think and feel without keeping up } & 0.668\end{array}$

appearances.

b.Secrets and information are kept confidential. $\quad 0.602$ 


\section{Supplementary information}

Supplementary information accompanies this paper at https://doi.org/10.1007/s40979-020-0051-3.

Additional file 1. ICAl's Academic Integrity Survey - for students (McCabe 2016) plus ethical behaviour.

\section{Abbreviations}

CE: Standardized coefficients; CNE: Non-standardized coefficients; ICAI: International Center for Academic Integrity; KMO: Kaiser, Meyer and Olkin; R2: Adjusted R squared; Sig: Significance

\section{Acknowledgements}

We thank Victoria Loncar and Veronica Montemayor for their valuable help English editing the manuscript.

\section{Declarations}

We confirm that this work is original and has not been published elsewhere, nor is it currently under consideration for publication elsewhere.

We will respond promptly to IJEl correspondence regarding reviewer comments, copyeditor revisions and publishing agreement.

\section{Authors' contributions}

G-D designed the study and collected the data, P-D performed the statistical analysis, H-E contributed with results analysis. All authors discussed the results and contributed to the final manuscript. All authors read and approved the final manuscript.

\section{Authors' information}

G-D. J. is Board Member of the International Center for Academic Integrity and Director of the Center for Integrity and Ethics at Universidad de Monterrey

\section{Funding}

Not applicable

\section{Availability of data and materials}

The datasets used and/or analyzed during the current study are available from the corresponding author on reasonable request.

\section{Competing interests}

The authors declare that they have no competing interests.

\section{Author details}

${ }^{1}$ Universidad de Monterrey, Av. Ignacio Morones Prieto 4500, 66238 San Pedro Garza García, Nuevo León, Mexico. ${ }^{2}$ Instituto Tecnológico de Estudios Superiores de Monterrey, Av. Eugenio Garza Sada 2501, 64849 Monterrey, Nuevo León, Mexico.

Received: 10 September 2019 Accepted: 26 January 2020

Published online: 17 February 2020

\section{References}

Amilburu, M. (2005). Literatura, virtudes y educación moral. http://www.redined.mec.es/oai/indexg.php?registro=01420073 001633

Ariely D (2013) The honest truth about dishonesty (first). Harper Collins Publishers, New York

Bertram-Gallant T (2016) Systems approach to going forward. In: Bretag T (ed) Handbook of academic integrity (First, pp. 975-978). Springer, Singapore

Blankenship KL, Whitley BE (2000) Relation of general deviance to academic dishonesty. Ethics Behav 10(1):1-12 Retrieved from http://ezproxy.udem.edu.mx/login?url=http://search.ebscohost.com/login.aspx?direct=true\&AuthType=ip\&db= a9h\&AN=3176620\&site $=$ ehost-live\&scope $=$ site

Bolívar A (2005) El lugar de la ética profesional en la formación universitaria. Rev Mex Investig Educ 10(24):93-123 Retrieved from http://www.redalyc.org/articulo.oa?id=14002406

Bosch M, Cavallotti R (2016) ¿Es posible una definición de integridad en el ámbito de la ética empresarial? Revista Empresa y Humanismo XIX(2):51-68. https://doi.org/10.15581/015.XIX.2.51-68

Connelly BL, Crook TR, Combs JG, Ketchen DJ Jr, Aguinis H (2018) Competence-and integrity-based trust in interorganizational relationships: which matters more? J Manag 44(3):919-945

EAFIT. (2016). Encuesta de auto-reporte de fraude académico

Fishman T (2016) Academic integrity as an educational concept, concern and movement in US institutions of higher education. In: Bretag T (ed) Handbook of academic integrity (First. Springer, Singapore, pp 7-22

García-Villegas M, Franco-Pérez N, y Cortés-Arbeláez A (2016) Perspectives on academic integrity in Colombia and Latin America. In: Bretag T (ed) Handbook of academic integrity, 1st edn. Springer, Singapore, pp 161-185

Gino F, Ariely D (2012) The dark side of creativity: original thinkers can be more dishonest. J Pers Soc Psychol 102(3):445

Hall TL, Kuh GD (1998) Honor among students: academic integrity and honor codes at state-assisted universities. NASPA 36(1):2-18

Harding TS, Passow HJ, Carpenter DD, Finelli CJ (2004) An examination of the relationship between academic dishonesty and professional behavior. Antennas Propagation Magazine, IEEE 46. https://doi.org/10.1109/MAP.2004.1388860 
Hayton JC, Allen DG, Scarpello V (2004) Factor retention decisions in exploratory factor analysis: a tutorial on parallel analysis. Organ Res Methods 7(2):191-205. https://doi.org/10.1177/1094428104263675

International Center for Academic Integrity. (2014). Fundamental Values of Academic Integrity. Retrieved from https:// academicintegrity.org/wp-content/uploads/2017/12/Fundamental-Values-2014.pdf

International Transparency. (2017). Corruption perceptions index 2017. Retrieved from https://www.transparwww. transparency.org/cpi

Kavanagh MH, Drennan L (2008) What skills and attributes does an accounting graduate need? Evidence from student perceptions and employer expectations. Accounting Finance 48(2):279-300. https://doi.org/10.1111/j.1467-629X. 2007.00245.x

Laduke RD (2013) Academic dishonesty today, unethical practices tomorrow? J Prof Nurs 29. https:/doi.org/10.1016/j. profnurs.2012.10.009

Lang JM (2013) Cheating lessons, learning from academic dishonesty (first). Harvard University Press, Cambridge

Lawson R (2004) Is classroom cheating related to business students' propensity to cheat in the "real world"? J Bus Ethics 49(2):189-199. https://doi.org/10.1023/B:BUSI.0000015784.34148.cb

Lombardo MM, Eichinger RW (2009) FYl: for your improvement: a guide for development and coaching (5th ed.). Minneapolis, MN: Lominger International: A Korn/Ferry Company.

Ma Y, McCabe D, Liu R (2013) Students' academic cheating in Chinese universities: prevalence, influencing factors, and proposed action. J Acad Ethics 11. https://doi.org/10.1007/s10805-013-9186-7

McCabe, D. (2016). Cheating and honor: lessons from a long-term research project. In T. Bretag, Handbook of academic integrity (First, p. 1097). Singapore: Springer

Nonis S, Swift CO (2001) An examination of the relationship between academic dishonesty and workplace dishonesty: a multicampus investigation. J Educ Bus 77. https://doi.org/10.1080/08832320109599052

Olt MR (2002) Ethics and distance education: strategies for minimizing academic dishonesty in online assessment. Online J Distance Learning Adm 5(3):1-7

Orosz G, Tóth-Király I, Bőthe B, Paskuj B, Berkics M, Fülöp M, Roland-Lévy C (2018) Linking cheating in school and corruption. Revue Européenne de Psychologie Appliquée 68(2):89-97. https://doi.org/10.1016/j.erap.2018.02.001

Payan J, Reardon J, Mccorkle DE (2010) The effect of culture on the academic honesty of marketing and business students. J Mark Educ 32(3):275-291. https://doi.org/10.1177/0273475310377781

Programa de las Naciones Unidas para el Desarrollo. (2015). Objetivos de Desarrollo Sostenible. Retrieved from https://www. undp.org/content/undp/es/home/sdgoverview/mdg_goals/mdg2/

Rigby D, Burton M, Balcombe K, Bateman I, Mulatu A (2015) Contract cheating \& the market in essays. J Econ Behav Organ 111:23-37. https://doi.org/10.1016/j.jebo.2014.12.019

Rose-Ackerman S, Palifka BJ (2016) Corruption and government: causes, consequences, and reform, 2nd edn. Cambridge University Press, New York

Sims RL (1993) The relationship between academic dishonesty and unethical business practices. J Educ Bus 68. https://doi. org/10.1080/08832323.1993.10117614

Stephens J, Romakin V, Yukhymenko M (2010) Academic motivation and misconduct in two cultures: a comparative analysis of US and Ukrainian undergraduates. Int J Educ Integr 6:47-60

Stephens JM (2016) Creating cultures of integrity: a multilevel intervention model for promoting academic honesty. In: Bretag T (ed) Handbook of academic integrity (First, pp. 995-1008). Springer, Singapore

Sultana F (2018) The false equivalence of academic freedom and free speech: defending academic integrity in the age of white supremacy, colonial nostalgia, and anti-intellectualism. ACME: An Int E-Journal for Crit Geographies 17(2):228-257

Thompson B (2004) Exploratory and confirmatory factor analysis: understanding concepts and applications, 1st edn. American Psychological Association, Washington, D.C.

UDEM. (2018). Encuesta de Integridad Académica

UNAM. (2013). Reporte de encuesta sobre percepción del plagio en la UNAM. Retrieved from http://www.eticaacademica. unam.mx/encuestas.pdf

Von Dran GM, Callahan ES, Taylor HV (2001) Can students' academic integrity be improved? Attitudes and behaviors before and after implementation of an academic integrity policy. Teach Bus Ethics 5(1):35-58

Winrow AR (2015) Academic integrity and the heterogeneous student body. Glob Educ J 2015(2):77-91 Retrieved from http://eds.b.ebscohost.com/eds/pdfviewer/pdfviewer?vid=1\&sid=4e798cc8-2b70-4094-8a36-117ad8990b24\%4 Osessionmgr101

\section{Publisher's Note}

Springer Nature remains neutral with regard to jurisdictional claims in published maps and institutional affiliations.

Ready to submit your research? Choose BMC and benefit from:
- fast, convenient online submission
- thorough peer review by experienced researchers in your field
- rapid publication on acceptance
- support for research data, including large and complex data types
- gold Open Access which fosters wider collaboration and increased citations
- maximum visibility for your research: over 100M website views per year
At BMC, research is always in progress.
Learn more biomedcentral.com/submissions

